\title{
Characterization at a local scale of a laser-shock peened aluminum alloy surface
}

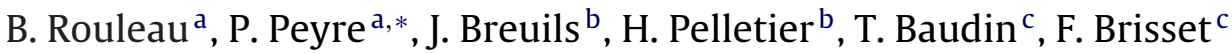 \\ a Laboratoire PIMM, UMR 8006 CNRS-Arts et Métiers Paris-Tech, 75013 Paris, France \\ ${ }^{\mathrm{b}}$ LISS, INSA de Strasbourg, 67084 Strasbourg, France \\ ' ICMMO, UMR CNRS 8182, Université Paris-Sud, 91405 Orsay Cedex, France
}

\begin{abstract}
A B S T R A C T
The influence of a laser shock peening mechanical surface treatment on 2050-T8 aluminum alloy has been investigated, mostly using Scanning Kelvin Probe Force Microscopy. Volta potential difference maps around $\mathrm{Al}(\mathrm{CuFeMn})$ precipitates were performed before and after laser-shock peening to determine the influence of laser treatment versus galvanic coupling near precipitates, and resulting pit initiations. It has been shown that laser shock peening either preserves or reduces precipitate-matrix Volta potentials gradients, which in this later case, and correlated to recent corrosion electrochemical investigations, could explain corrosion improvement obtained after laser-shock peening treatments of aluminum alloys. The influence of crystal orientation and plastic deformation, and more specifically the effect of laserinduced compressive residual stresses or work-hardening, on the Volta potential values and on the pitting corrosion behavior was also addressed.
\end{abstract}

Keywords:

Laser-shock peening

Scanning Kelvin Probe Force Microscopy

Work function

Deformation

\section{Introduction}

The 2050, a new generation $\mathrm{Al}-\mathrm{Cu}-\mathrm{Li}$ alloy, has been recently developed for aeronautical applications because of its good specific strength and better stress corrosion resistance compared to other aluminum alloy [1]. Thus, it is now envisaged for the stiffening parts of commercial aircrafts.

Unfortunately this alloy suffers from exfoliation corrosion and pitting corrosion in chloride environment due to the presence of $\mathrm{Al}(\mathrm{CuFeMn})$ intermetallic phase [2-4]. These precipitates behave as cathodic sites and the dissolution of the matrix around precipitates is observed during corrosion tests in chloride media [5].

Lately, a newly developed laser application called laser-shock peening (LSP) allows to deform plastically the surface of metals by the generation of a high pressure plasma that subsequently induces residual stresses in the target [6]. As the surface is usually covered by a protective layer (paint, adhesive), the laser treatment becomes purely mechanical and compressive residual stresses affect several hundred of micrometers, without chemical modifications of surface layers. The interest for this treatment was leaned on recent researches on stainless steels treated by LSP, which indicated an improvement of pitting corrosion resistance and a decrease of corrosion currents in chloride solutions [7,8]. Consequently, such LSP treatment was recently applied to 2050-T8 alloy to investigate its influence versus localized corrosion resistance investigated at

\footnotetext{
* Corresponding author.

E-mail address: patrice.peyre@ensam.eu (P. Peyre).
}

global or local scales in chloride environment $[9,10]$. Better electrochemical behaviors were demonstrated with electrochemical micro-cells, more specifically in the aluminum matrix (large anodic shifts, no more pitting), and to a more limited extent around nonmetallic inclusions after LSP treatment. These improvements were globally attributed to the compressive residual stress field induced by LSP (near $-300 \mathrm{MPa}$ averaged value in a $10 \mu \mathrm{m}$-thick surface layer), and to a mechano-electrochemical like effect. However, additional experimental contributions are necessary to understand more precisely the benefits from LSP, using techniques, considering phenomena at a more local scale. One of the available technique for investigating laser-shock peened surfaces at a sub-micron scale is Scanning Kelvin Probe Force Microscopy (SKPFM).

One of the objectives of our work is to understand the changes in the electrochemical behavior of the 2050-T8, mainly employing the SKPFM. This technique allows measuring the Volta potential $\Delta \psi$ or contact potential difference $\Delta V_{\mathrm{CPD}}$ which corresponds to the difference of work functions between a scanning tip and an interrogated surface. The Volta potential $(\psi)$ is defined by the combination of the surface potential $(\chi)$ corresponding to the energy required to cross the metal interface (due to oriented dipoles) and of the Galvani potential $(\varphi)$ which is the potential inside the metal:

$\varphi=\chi+\psi$

More precisely, the Volta potential difference between two metal is defined as the electrical potential difference in vacuum between one point close to the surface of the first metal and another point close to the second metal surface, where both metals are uncharged and then brought into electrical contact. 
Similarly [19], the work-function $\Phi$ is the sum of the electron chemical potential $\mu_{\mathrm{e}}$, and of the energy required to move an electron outside the metal through the interface (charge $e \times$ surface potential $\chi$ ):

$\Phi=-\mu_{\mathrm{e}}+e \chi$

Considering two different surfaces, the work-function difference $\Delta \Phi$ can thus be correlated to the surface potential difference $\Delta \chi$ according to:

$\Delta \Phi=e \Delta \chi$

Since Schmutz and Frankel [11] have shown a correlation between Volta potential differences measured on aluminum alloy surfaces and corrosion behavior, such technique has been widely used to predict the corrosion behavior of different alloy surfaces. Usually, the authors focused on the determination of potential gradients between matrix and precipitates to indicate the nobility of the precipitates relative to the matrix [11-17]. As work functions of noble materials are higher than the ones of lesser noble materials, a cathodic behavior is usually expected to be due to higher work functions. A good example is copper-rich precipitates in aluminum alloys. For instance, recent investigations on 2024 alloy by Campestrini et al. [12], have shown not only a difference in Volta potential between the matrix and the precipitates but also a huge difference in potential (about $400 \mathrm{mV}$ ) inside shell-shaped precipitates, due to chemical composition gradients between the core (AlCuMnFeSi) and the shell (AlCuMg) of precipitates.

Although this technique is now widely used in corrosion science, some authors have pointed out the limitations of SKPFM. First, in [18], SKPFM measurements are carried out on dry surfaces whereas corrosion phenomena occur on immersed samples. This generates an extra-complexity due to the establishment of an electrical double layer at the metal-solution interface. Second, Rohwerder et al. have also demonstrated on Fe and Nb samples that, even if Volta potential differences measured on aluminum alloys correlate with corrosion behavior, such correlation cannot be considered as a general rule and must be checked for each new alloy [18].

Moreover, even if surfaces are very often polished to avoid topographical artefacts when Volta potential maps are acquired [18,19], other authors [20] consider that ultramicrotomy is the best sample preparation to avoid altering the chemical composition and to produce a very smooth surface.

In the following, we will investigate Volta potential gradients between Al matrix and non-metallic inclusions on as-polished and laser-shock peened 2050-T8 specimens, in order to provide an experimental support to recent corrosion analysis that have demonstrated benefits from LSP treatment versus pitting corrosion resistance $[5,10]$.

More widely, the influence of surface modifications such as work-hardening and residual stresses versus work function measurements, and corrosion behavior will also be discussed.

\section{Experimental}

The alloy used in this work was a 2050-T8 (Al-3.73Cu-0.9Li-0.3Mg-0.05Fe-0.37Mn-0.009Zr), provided by EADS Innovation Works $C^{\text {ie }}$ in $15 \mathrm{~mm}$ thick plate. $14 \mathrm{~mm}$ diameter $-7.5 \mathrm{~mm}$ thick cylinders were extracted from this plate. The samples were then mechanically polished using SiC paper (1000, 2400, 4000 grades) and then followed by 3 and $1 \mu \mathrm{m}$-size abrasive diamond paste. After polishing, samples were cleaned by ultrasounds, rinsed by ethanol and blown dried by air.

Laser-shock peening was carried out in water confinement regime (Fig. 1) using a frequency-doubled Nd:YAG laser $(\lambda=532 \mathrm{~nm})$ delivering up to $1.3 \mathrm{~J}$ in $9 \mathrm{~ns}$ pulse duration at a

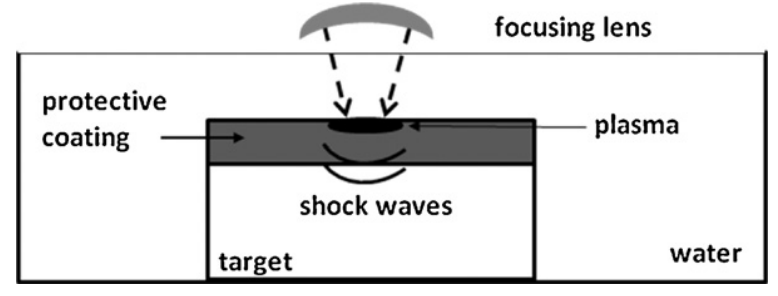

Fig. 1. Laser-shock peening in confined ablation mode.

$10 \mathrm{~Hz}$ cadency rate. The $1.5 \mathrm{~mm}$ diameter impacts were used at $5-7 \mathrm{GW} / \mathrm{cm}^{2}$ laser intensity with a $50 \%$ overlapping ratio. Prior to laser treatment, all samples were protected from thermal effects by an $80 \mu \mathrm{m} \mathrm{Al}$ adhesive, in order to ensure a pure mechanical LSP treatment.

Scanning Electron Microscopy (SEM) experiments were undertaken using a Hitachi 4800 device operated at $15 \mathrm{kV}$ and equipped with an energy dispersive X-ray analysis system (EDS) to localize the precipitates and determine their morphology and their composition.

Electron Back Scattered Diffraction (EBSD) tests were carried out on a sequence of juxtaposed $\sim 0.8 \mathrm{~mm} \times \sim 2.3 \mathrm{~mm}$ operating windows using a FEG-SEM system using an automatic combination of stage and beam moves. The same area of about $8.5 \mathrm{~mm} \times 5.5 \mathrm{~mm}$ was analyzed before and after LSP. The indexation of the Kikuchi lines was made automatically using the TSL-OIM ${ }^{\mathrm{TM}}$ software. Prior to EBSD analysis, the surface was polished with a sub-micron $\mathrm{SiO}_{2}$ suspension in order to remove work-hardened layers due to the mechanical polishing, and favor the indexation. The high voltage and the current were respectively of $25 \mathrm{kV}$ and $\sim 2 \mathrm{nA}$ with a scan step of $2 \mu \mathrm{m}$ and an acquisition speed of more-than-100 pts/s. The purpose of EBSD experiments was twice: (1) to check a possible effect of crystal orientation on the matrix-precipitate potential gradients, and (2) to estimate the influence of LSP treatment on crystal disorientation, and on the resulting galvanic coupling between adjacent grains.

Hardness measurements were carried out on a Vickers Hardness tester at a constant $50 \mathrm{~g}$ load. Residual stresses were estimated using the X-ray diffraction technique and the $2 \Theta=f\left(\sin ^{2} \Psi\right)$ method, with a $\mathrm{Cr}$ anticathode, and $\{311\}$ planes as local strain gauges.

Nanoindentation tests were performed to evaluate mechanical properties of tested samples using a Nano Indenter ${ }^{\circledR}$ XP (Agilent Technologies Inc). The main objective was to analyze very surface work-hardening changes induced by LSP, and their conceivable influence on surface reactivity via mechano-electrochemical effects [10].

During such a test, an indenter with known geometry is loaded up to the instruction load (using 3 loading and unloading cycles) at a constant loading rate. Analyses of load-displacement curves allow the identification of young modulus, $E$, and hardness, $H$, of tested samples. All indenters were calibrated on three references materials $\left(\mathrm{Si}, \mathrm{SiO}_{2}\right.$ and $\left.\mathrm{Al}\right)$. The first set of experiments was performed using the XP head of the apparatus, equipped with diamond Berkovich indenter tip, to compare mechanical behavior of the 2050-T8 sample before and after the laser treatment. Maximum applied loads then ranged from 1.25 to $5 \mathrm{mN}$, which correspond to penetration depths of 140-300 $\mathrm{nm}$ for both samples. A second set of experiments was performed in order to assess $\mathrm{Al}(\mathrm{FeCuMn}$ ) precipitates and the neighboring matrix mechanical behavior using the DCM (Dynamic Contact Module) head of the Nano Indenter apparatus, using instruction load between 25 and $100 \mu \mathrm{N}$. $\mathrm{Al}(\mathrm{FeCuMn})$ precipitates were localized using an in situ AFM microscope inside the nanoindentation apparatus.

SKPFM was performed in order to determine the relative Volta potentials of the $\mathrm{Al}(\mathrm{FeCuMn})$ precipitates before and after the laser 

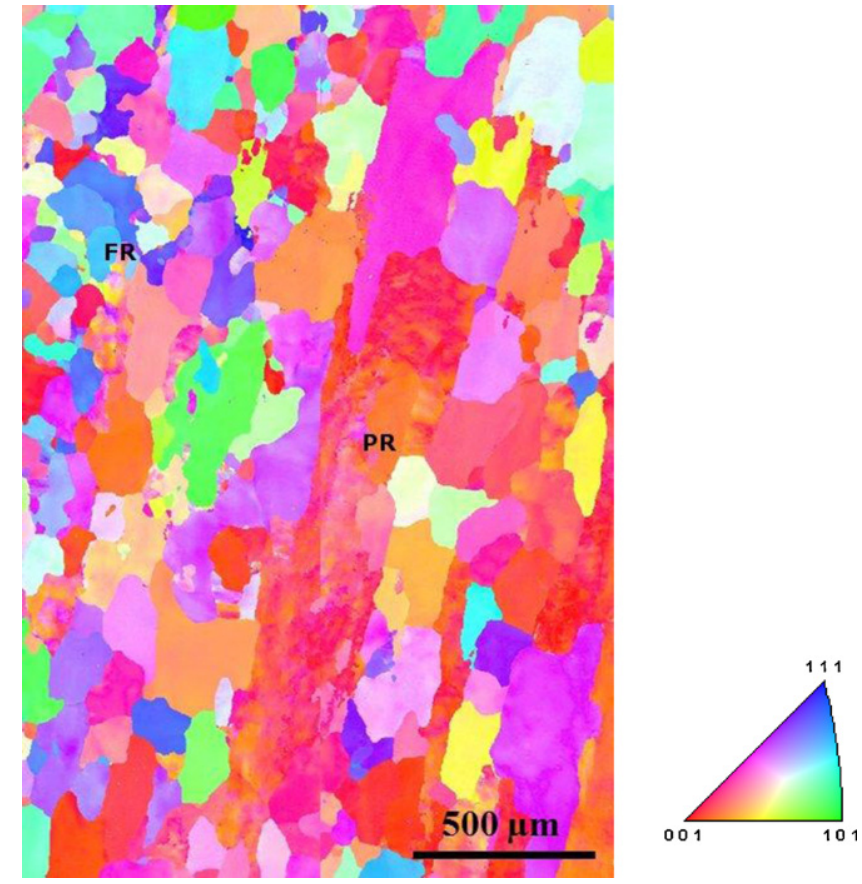

Fig. 2. EBSD analysis of the grain distribution and orientation in 2050-T8 alloy (FR = fully recrystallized zone, $P R=$ partially recrystallized zone with a deformation substructure).

treatment. Topography and Volta potentials were mapped using a Veeco SPM device (Multimode, Nanoscope V controller), in air at room temperature and ambient humidity, with conductive metalcoated probes which are oscillated at a resonant frequency near $70 \mathrm{kHz}$. The mappings were collected in the lift mode [21], which is a two-pass method. In the first pass, the topography of the sample is recorded using the tapping mode [22]: no external voltage is applied to the tip and the cantilever is mechanically vibrated near its resonant frequency by a piezoelectric element. On the second pass to measure the Volta potential, the tip is lifted at a selected distance and scanned the same line recorded in the first pass. During this pass, the piezo-element is turned off and an oscillating voltage $V_{\mathrm{ac}} \sin \omega t$ is applied to the tip. A $V_{\mathrm{dc}}$ potential is added to the previous voltage to nullify the vibration amplitude of the cantilever and obtain the Volta potential map of the sample with respect to the tip. A lift scan height of $10-20 \mathrm{~nm}$ led to the best potential lateral resolution.

On each sample, the experimental procedure that we used for investigating surfaces is as follows: (1) Vickers indentation to localize specific areas, (2) SEM/EDS identification of 20 precipitates per sample (size + chemical content), (3) SKPFM of the same precipitates to have potential gradients before LSP, (4) LSP treatment followed by ethanol US cleaning, and (5) SKPFM analysis after LSP.

Two different samples were analyzed with this procedure, resulting in 50 different precipitates analyzed before and after LSP, at different locations of each sample. Using this procedure, the time between the two SKPFM investigations was approximately 2 days.

\section{Results}

\subsection{The as-received 2050-T8 microstructure}

EBSD analysis shows large (between $50 \mu \mathrm{m}$ and $700 \mu \mathrm{m}$ ) and oriented grains with inhomogeneous crystallization level as shown by EBSD data (Fig. 2).

After the $\mathrm{T} 8$ treatment, the dispersion-strengthening $\mathrm{Al}_{2} \mathrm{CuLi}$ T1 phase in the form of $50-100 \mathrm{~nm}$ plates is expected to be found

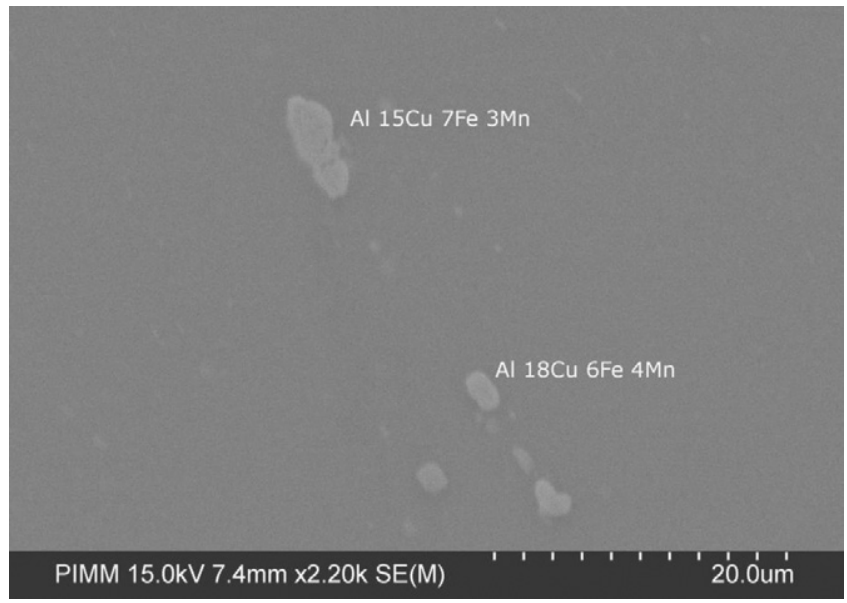

Fig. 3. $\mathrm{Al}(\mathrm{CuFeMn})$ precipitates orientated along the rolling direction SL in 2050-T8 alloy.

within the grains $[1,3]$. The resulting global yield strength is surprisingly quasi-isotropic, with approximately $510 \mathrm{MPa}$ value on both $-\mathrm{L}$ and $-\mathrm{T}$ directions.

Using SEM/EDS, wide $\mathrm{Al}(\mathrm{CuFeMn})$ intermetallic precipitates are evidenced, having a maximum size up of $10 \mu \mathrm{m}$. These precipitates are uniformly distributed along the rolling direction, with chemical composition $75.2 \pm 10.4$ at.\% $\mathrm{Al}, 15.2 \pm 10$ at.\% Cu, $6 \pm 3$ at.\% Fe and $3.5 \pm 3$ at.\% Mn, (Fig. 3). These results indicate a great scatter in the copper concentration (values between 5 and 25 at.\% $\mathrm{Cu}$ ). This inhomogeneity is expected to have non-negligible effect on the behavior of the alloy in a chloride environment.

To investigate precipitates surroundings before and after LSP, Vickers hardness indents were carried out just after polishing. This allowed us to analyze the same areas with SEM and AFM-SKPFM techniques.

\subsection{Morphological and Mechanical surface modifications induced by LSP treatment}

LSP modifies surface topography and provokes a periodic undulation, corresponding to impact overlaps (Fig. 4). For LSP conditions, the peak-to-valley distance is approximately $500 \mu \mathrm{m}$, and the maximum height difference $\Delta z$ is near 3-4 $\mu \mathrm{m}$. This also results in an increase of roughness parameter Ra (Table 1 ).

Concerning mechanical modifications, as already shown in previous publications [6], LSP generates work-hardening, due to the plastic deformation induced by laser-induced shock waves. On

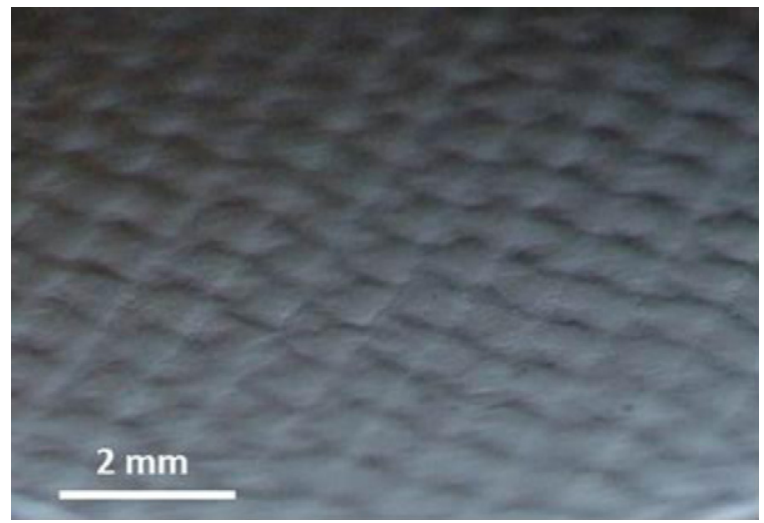

Fig. 4. LSP treatment at $50 \%$ overlap ( $1.5 \mathrm{~mm}$ impacts $-6 \mathrm{GW} / \mathrm{cm}^{2}$ ) of 2050 -T8 alloy - Formation of peaks and valleys (2-4 $\mu \mathrm{m}$ height) due to the impact overlaps. 
Table 1

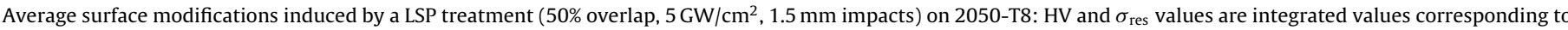
a 10-12 $\mu \mathrm{m}$ analyzed depth, $H_{\mathrm{B}}$ and $E_{\mathrm{B}}$ values are identified properties from nanoindentation tests at $1.25 \mathrm{mN}$ load.

\begin{tabular}{|c|c|c|c|c|c|c|}
\hline Surface preparation & $R_{\mathrm{a}}(\mu \mathrm{m})$ & $R_{\mathrm{t}}(\mu \mathrm{m})$ & $H V_{0.05}(\mathrm{GPa})$ & $\sigma_{\text {res }}(\mathrm{MPa})$ & $H_{\mathrm{B}}(\mathrm{GPa})$ & $E_{\mathrm{B}}(\mathrm{GPa})$ \\
\hline Polishing & 0.04 & 0.2 & 1.3 & $-40 \pm 40$ & $2.1 \pm 0.15$ & $83 \pm 12$ \\
\hline Polishing + LSP & 0.5 & 2.7 & 1.5 & $-290 \pm 50$ & $2.1 \pm 0.15$ & $83 \pm 12$ \\
\hline
\end{tabular}

2050-T8 alloy, the resulting effect is $a+20 \%$ maximum hardening (1.3-1.5 GPa with a Vickers Hardness tester at $50 \mathrm{~g}$ load), and the generation of a compressive residual stress field ( -290 Mpa maximum value identified by X-ray diffraction, a $\mathrm{Cr}$ anticathode, and $\{311\}$ planes, corresponding to a $11 \mu \mathrm{m}$ penetration depth of $\mathrm{X}$ rays).

Additional investigations affecting lower depths (1-2 $\mu \mathrm{m}$ vs 10-20 $\mu \mathrm{m}$ ), such as nanoindentation tests were also carried out. As shown in Fig. 5, nanoindentation testing using a Berkovich sharp indenter indicated a quasi-negligible work-hardening effect of LSP (within the error bars), especially for very small indented depths, and even some possible softening effects [5], on the very first surfaces layers. If we consider for instance, a $130 \mathrm{~nm}$ vertical displacement of the indent (for a $1.25 \mathrm{mN}$ load), the investigated layer is approximately $1 \mu \mathrm{m}$, and no distinction can be made between as polished and laser-peened surfaces (Fig. 5a). Both exhibit surface hardness near $2.1 \pm 0.15 \mathrm{GPa}$ (Fig. 5b).

Such results are rather logical if we consider previous grazing incidence X-ray diffraction (GIXRD) tests [5] which have revealed low tensile residual stress localized at the very surface $(1 \mu \mathrm{m}$ indepth) of 2050-T8 after LSP. However, this unexpected softening effect could not be explained by the LSP process in itself which is expected to provide a pure mechanical loading, and compressive stresses.

Additional tests were carried out to characterize precipitates with low applied loads $(25-100 \mu \mathrm{N})$, resulting in penetration depths of $12-32 \mathrm{~nm}$ in the matrix and $7.5-17.5 \mathrm{~nm}$ in the precipitates (Figs. 6 and 7). They revealed much higher hardness values for the $\mathrm{Al}(\mathrm{CuFeMn})$ precipitates $(H=15 \pm 2 \mathrm{GPa})$ than for the sur-
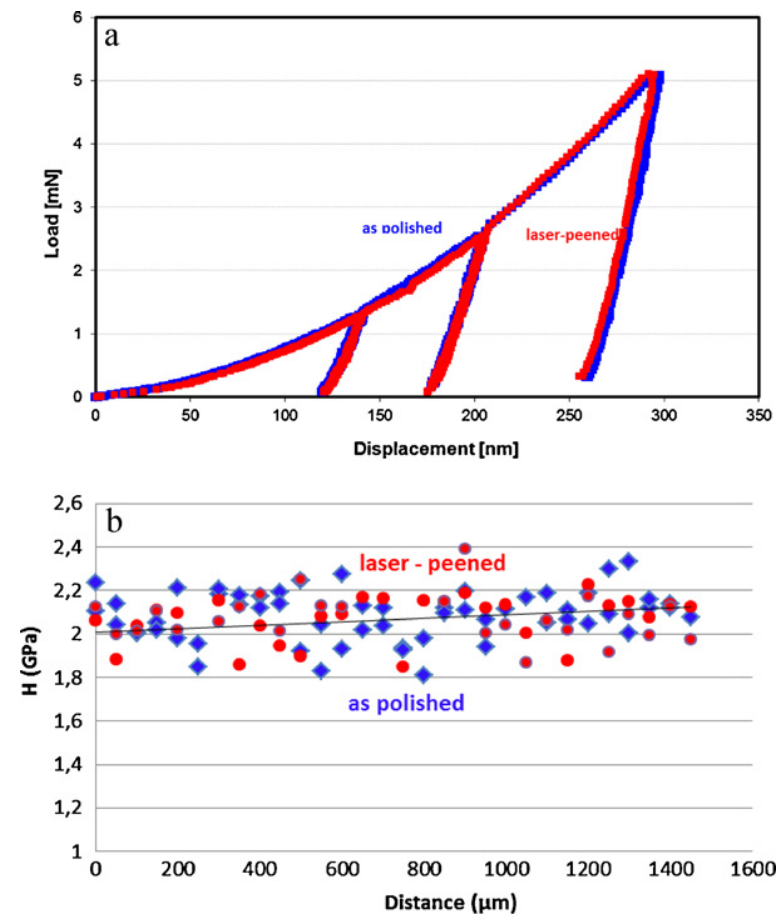

Fig. 5. Nanoindentation analysis with a Berkovich indentor of as polished and laserpeened 2050-T8 surfaces (a): load-displacement curves for $1.25 \mathrm{mN}, 2.5 \mathrm{mN}$ and $5 \mathrm{mN}$ loads, (b) hardness filiations carried out on the samples surface.

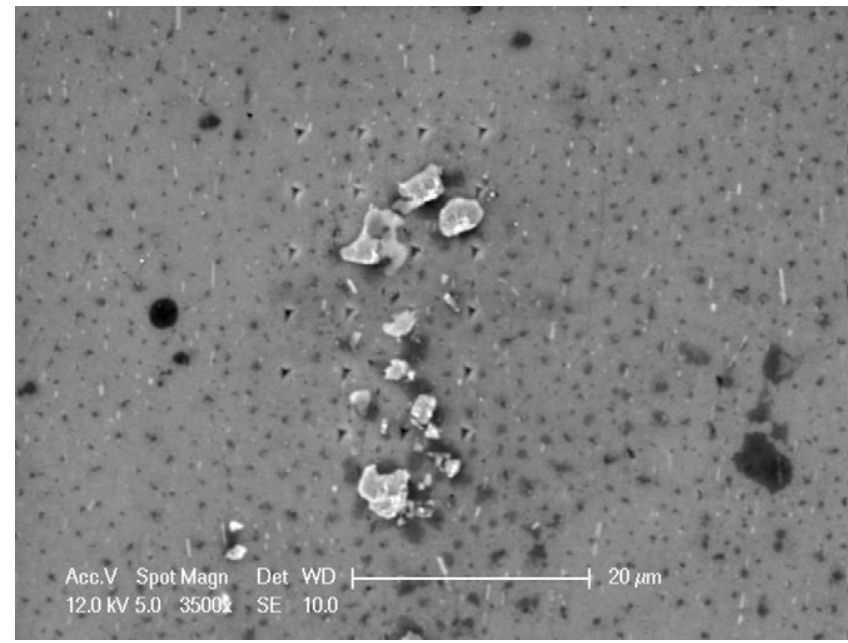

Fig. 6. SEM picture scans of nanoindentation tests carried out near AlFeCuMn precipitates on a 2050-T8 as-polished sample (indentation depth $=0.2 \mu \mathrm{m}$ ).
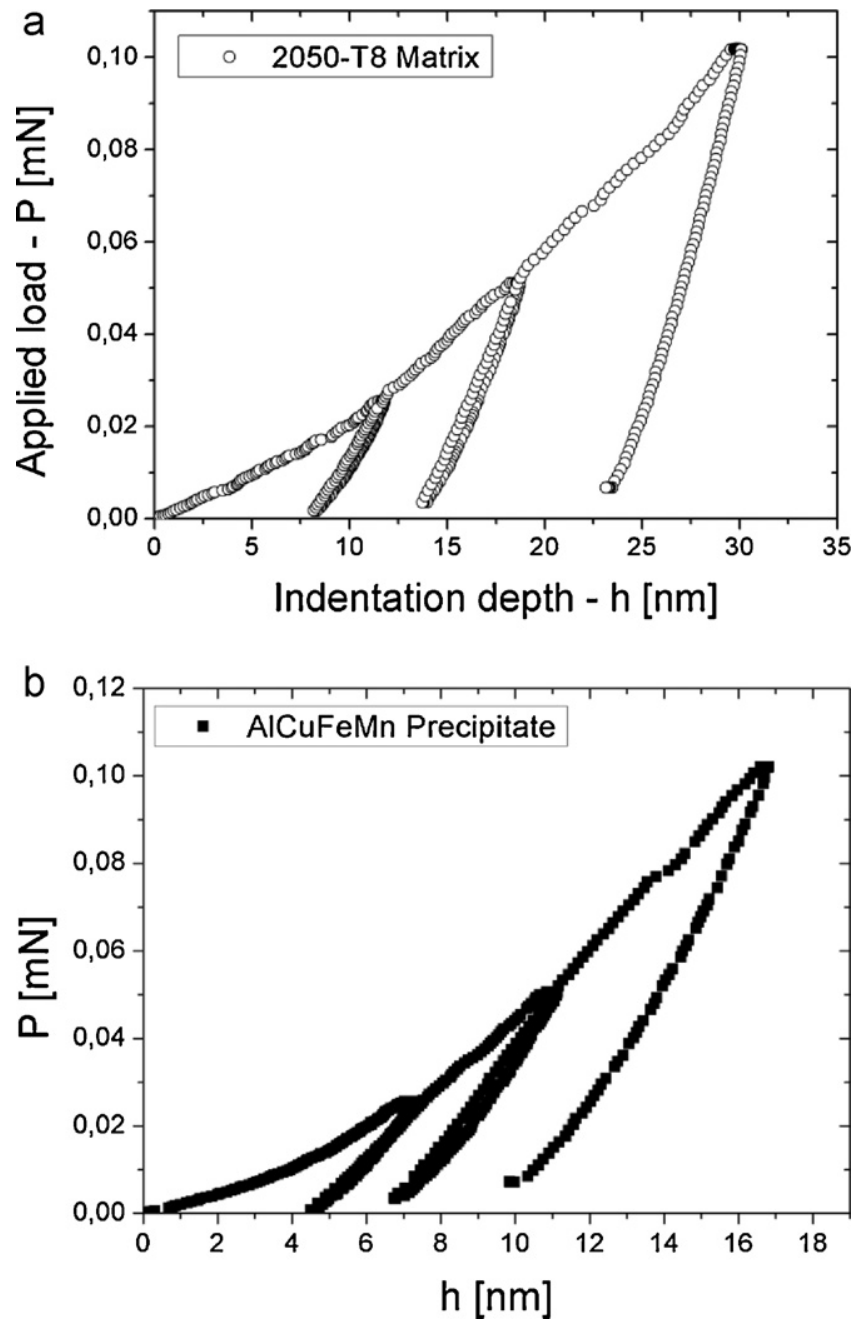

Fig. 7. Examples of experimental load-displacement curves obtained from nanoindentation tests with the DCM head on (a) the 2050-T8 matrix and (b) $\mathrm{Al}(\mathrm{CuFeMn})$ precipitates. 

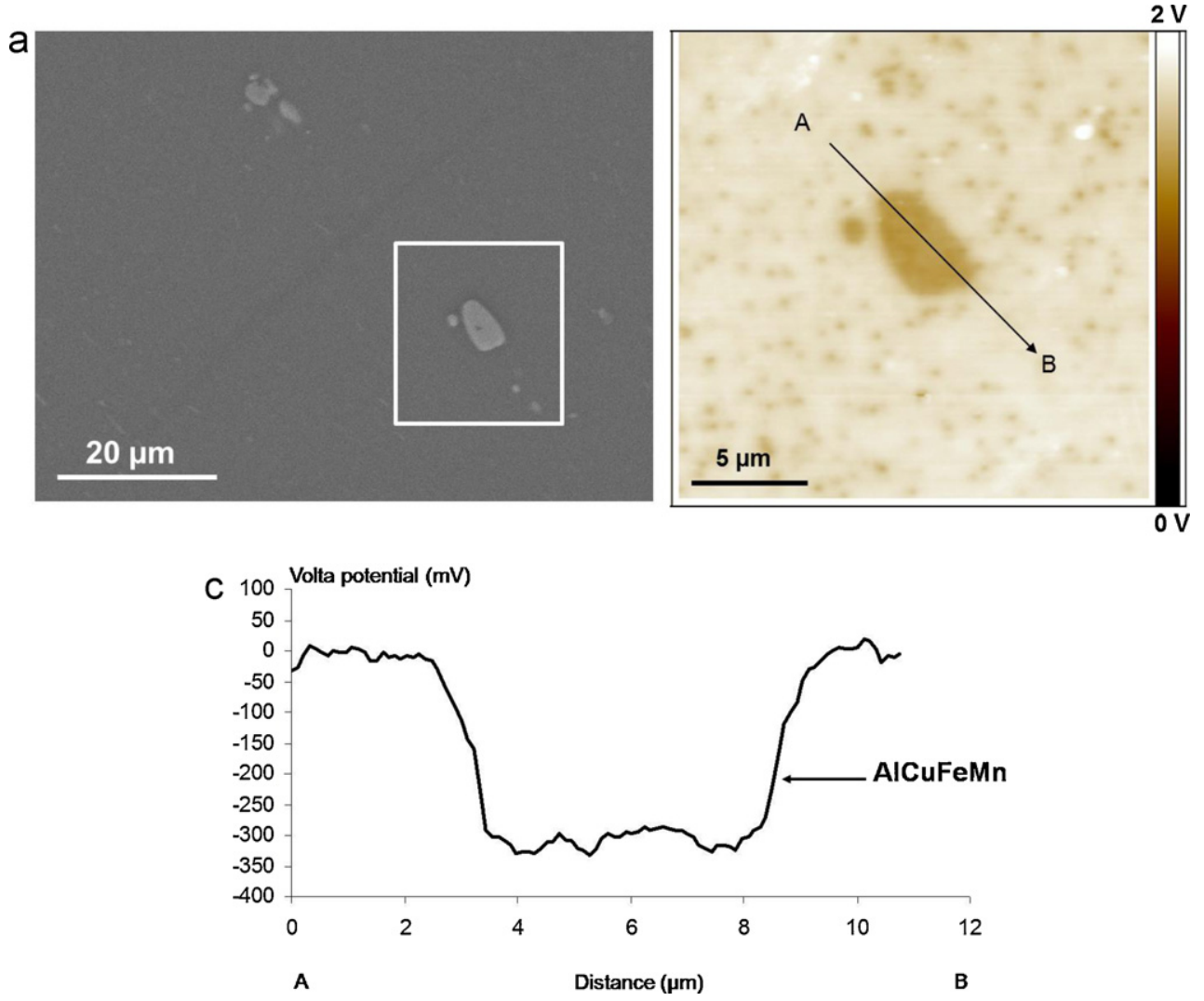

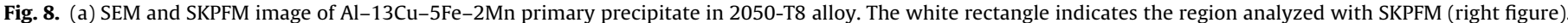
(b) Line-profile analysis of Volta potential difference between $\mathrm{Al}(\mathrm{CuFeMn})$ precipitate and the $\mathrm{Al}$ surrounding matrix.

rounding AlCuLi matrix $(H=4.2 \pm 0.6 \mathrm{GPa})$, but no real modification after LSP treatment.

\subsection{SKPFM results}

SKPFM measurements have been carried out on the same $\mathrm{Al}(\mathrm{CuFeMn})$ precipitates before and after LSP treatment. The variation in contact potential gradients was estimated and discussed.

\subsubsection{Analysis of the as-polished 2050-T8}

Fig. 8a and b shows SEM and SKPFM images of the same $\mathrm{Al}-13 \mathrm{Cu}-5 \mathrm{Fe}-2 \mathrm{Mn}$ precipitate. More in detail, Fig. $9 \mathrm{~b}$ presents both the topography (left) and Volta potential (right) maps at the surface of the as-polished 2050-T8 alloy. Bright regions correspond to increased heights and Volta potential respectively. After polishing, Vickers indents made on the surface alloy allow detecting the areas previously investigated by SEM, with the AFM device. Consequently, as precipitates are sometimes barely visible in the topography map, their presence is confirmed by the Volta potential map (Fig. 8b right). Topographically, the $\mathrm{Al}(\mathrm{CuFeMn})$ precipitates are slightly higher $(+10 \mathrm{~nm}$ to $+30 \mathrm{~nm})$ than the matrix after polishing. This was attributed to a better erosion resistance due to higher hardness of precipitates versus the matrix (see Section 3.2).

As mentioned before, the $\mathrm{Al}(\mathrm{CuFeMn})$ precipitates display lower potential relative to the adjacent matrix, which are not due to a change in topography (Fig. 8b left). For instance, the lineprofile analysis of the $\mathrm{Al}(\mathrm{CuFeMn})$ precipitate has a potential of around $-300 \mathrm{mV}$ relative to the matrix (Fig. 8c). Potential gradients comprised between $-150 \mathrm{mV}$ and $-550 \mathrm{mV}$ were systematically registered in our study. These $\mathrm{Al}(\mathrm{CuFeMn})$ precipitates have a darker contrast in Volta potential map, but are nobler than the adjacent matrix, due to an inversion of the potential determination, already mentioned by several authors [11]. In this paper, we chose not to invert the output potential signal, and present as-measured potential values. In turn, the amplitudes of surface potentials and gradients are in accordance with those of Viejo et al. [3,4] on the same 2050-T8 alloy.

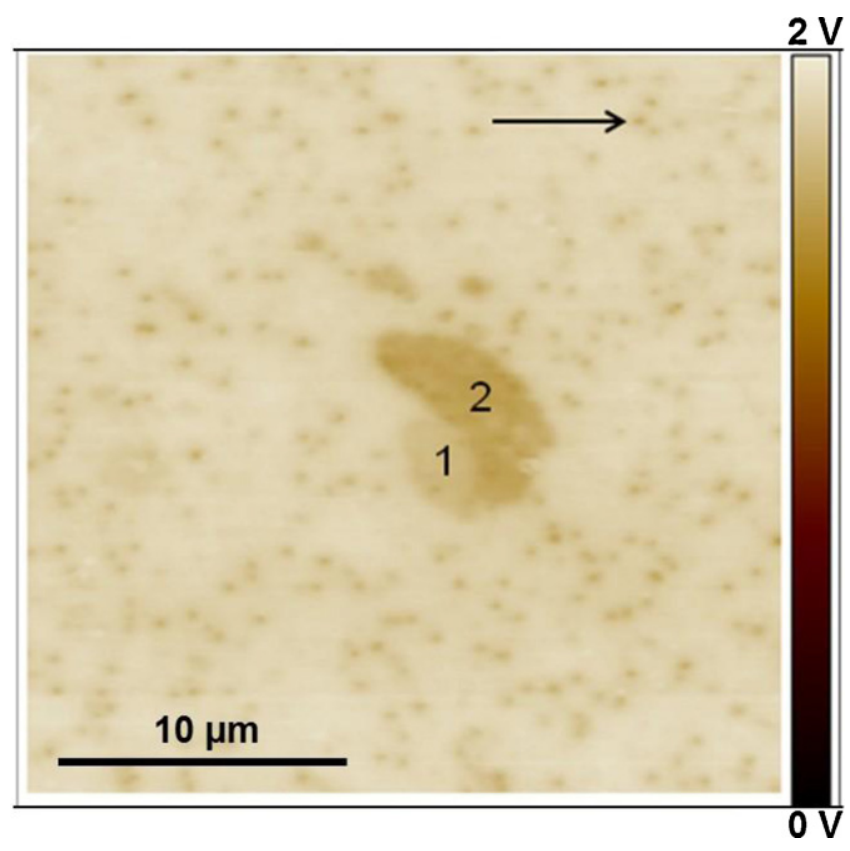

Fig. 9. Volta potential map of a 2050-T8 as-polished surface: $\mathrm{Al}(\mathrm{CuFeMn})$ primary precipitate with a dual Cu content $(1=7 \% \mathrm{Cu}, 2=17 \% \mathrm{Cu})$, and $100-200 \mathrm{~nm} \mathrm{Al}_{3} \mathrm{Zr}$ or $\mathrm{Al}_{2} \mathrm{CuLi}$ dispersoïds (black arrow). 

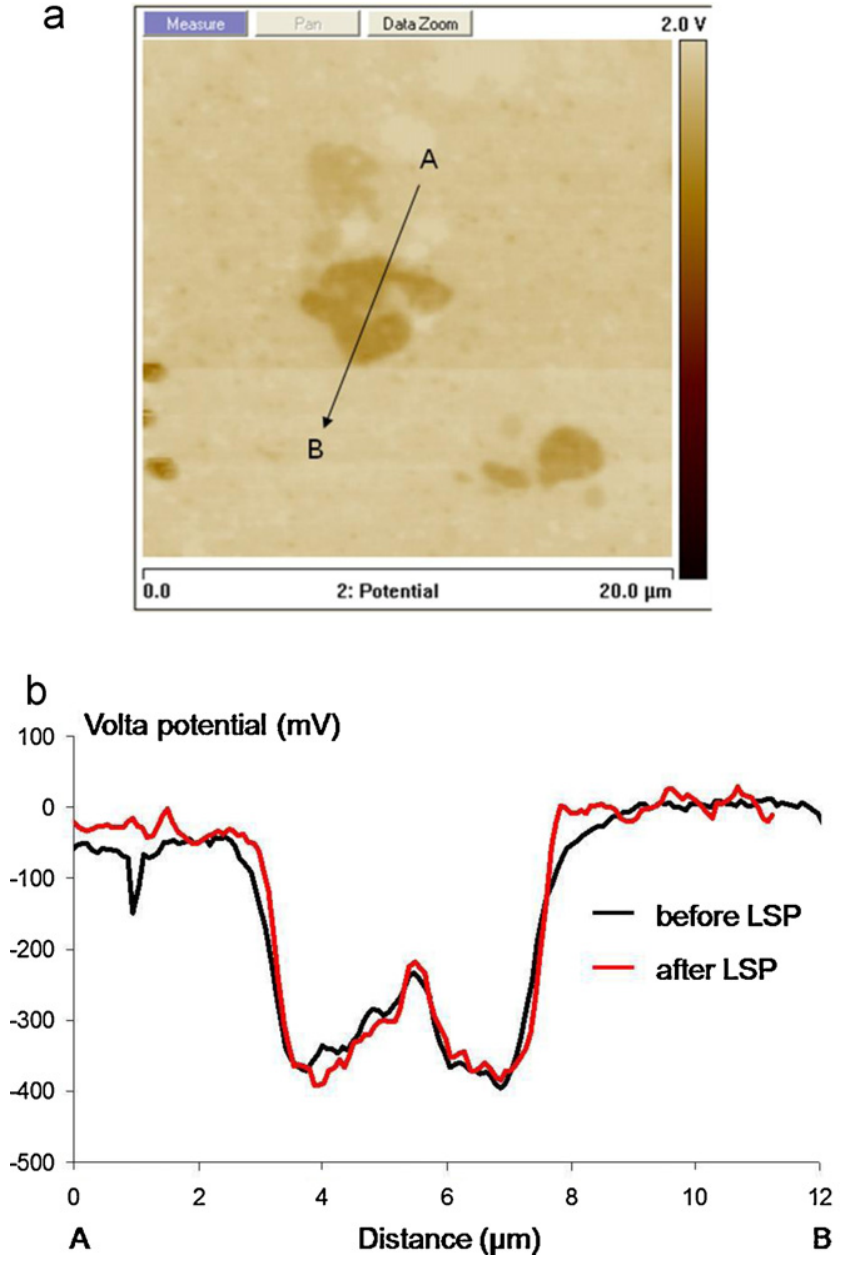

Fig. 10. (a) Volta potential map showing differences between a $\mathrm{Al}(\mathrm{CuFeMn})$ precipitate and Al matrix before LSP. (b) Line-profile analysis comparing the Volta potential difference between $\mathrm{Al}(\mathrm{CuFeMn})$ precipitate and the $\mathrm{Al}$ matrix surrounding before and after LSP treatment.

Similarly, small (near $100 \mathrm{~nm}$ ) dark spots are also seen in the potential maps displayed Figs. $8 \mathrm{~b}$ (right) and 9. These nano-sized areas are probably $\mathrm{Al}_{2} \mathrm{CuLi}-\mathrm{T} 1$ strengthening phases or $\mathrm{Al}_{3} \mathrm{Zr}$ dispersoids $[1,3,4]$, and are also nobler than the matrix.

Moreover, on the same $\mathrm{Al}(\mathrm{CuFeMn}$ ) precipitate (Fig. 9) two areas noted 1 and 2 can have distinct concentration of $\mathrm{Cu}$. Logically, the area 2 having a higher $\mathrm{Cu}$ content ( $\sim 17$ at.\%) is $-250 \mathrm{mV}$ relative to the matrix and more noble than the area $1(\sim 7$ at.\%) with only $-150 \mathrm{mV}$ gradient. This contrast within the precipitate is visible because a great difference of $\mathrm{Cu}$ content exists inside the same precipitate. However, it should be pointed out that SKPFM images the very surface whereas the EDX analyses determine the elemental composition of the sample volume (about $1 \mu \mathrm{m}^{3}$ ). Thus the composition at the very surface could change from one precipitate to the next and could explain the scattering observed in the potential values. However, considering the large number of precipitates to matrix potential difference, no clear correlation could be statistically evidenced (on 50 precipitates) between their $\mathrm{Cu}$, Fe or $\mathrm{Mn}$ contents and the potential gradients.

\subsubsection{SKPFM analysis of a laser-shock peened 2050-T8 surface}

In order to investigate the influence of LSP treatment on the Volta potential difference, the same $\mathrm{Al}(\mathrm{CuFeMn})$ precipitates were observed before and after treatment.

Very small topography changes are detected in the vicinity of precipitate-matrix after LSP, with a tendency to increase height gra- a
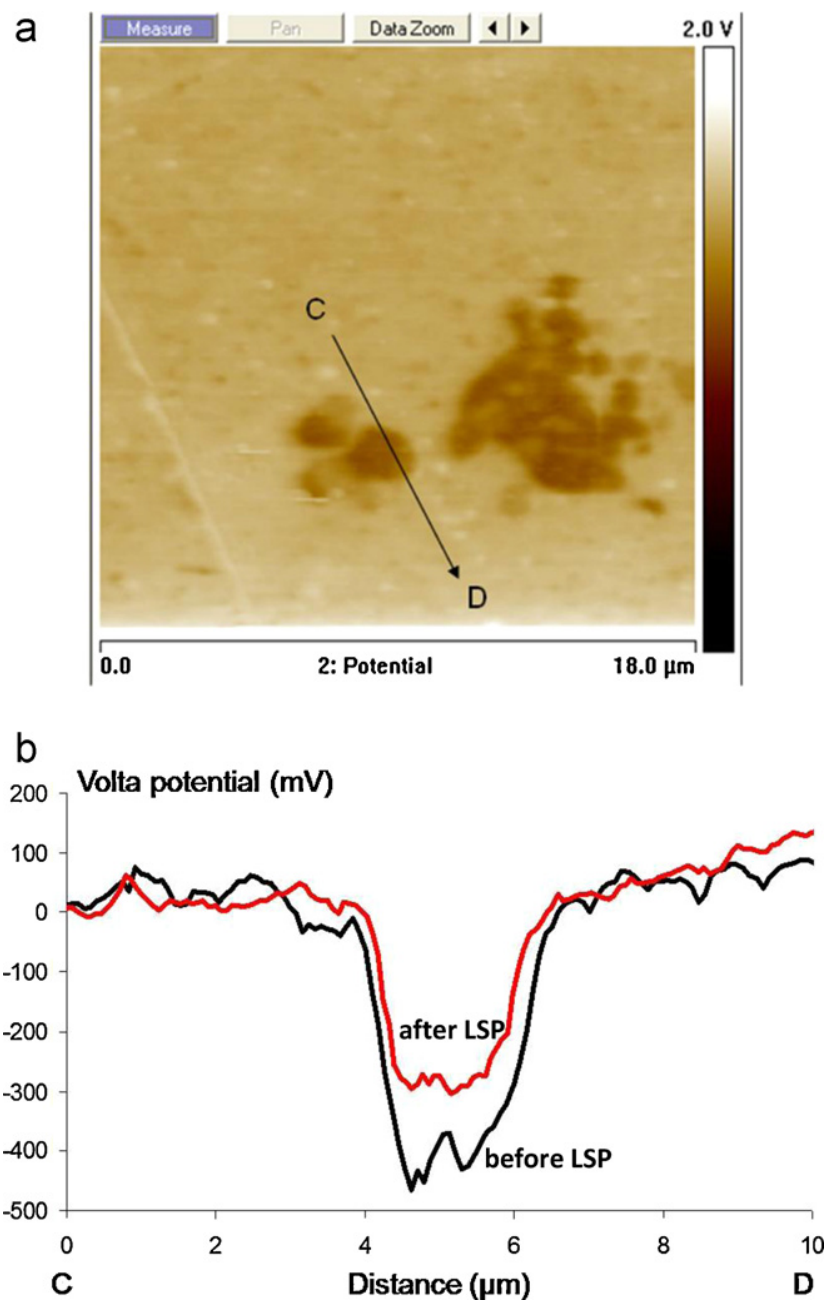

Fig. 11. (a) Volta potential map showing differences between a $2 \mu \mathrm{m} \mathrm{Al}(\mathrm{CuFeMn})$ precipitate and Al matrix after LSP. (b) Line-profile analysis revealing a reduction of Volta potential differences between $\mathrm{Al}(\mathrm{CuFeMn})$ precipitate and the $\mathrm{Al}$ matrix after LSP treatment.

dients ( $+10 \mathrm{~nm}$ to $+20 \mathrm{~nm}$ ), due to a more severe deformation of the ductile matrix ( $\S 3.2$ ). Moreover, all precipitate-matrix interfaces were sound (no debonding) after LSP treatment.

On the first example shown in Fig. 10, the Volta potential difference map the $\mathrm{Al}(\mathrm{CuFeMn})$ precipitate is $-250 \mathrm{mV}$ to $-400 \mathrm{mV}$ versus the matrix, both before and after the LSP treatment which confirms the cathodic nature of precipitate with respect to the matrix and indicates that the Volta potential difference has been kept constant after LSP. In the second example (Fig. 11), the Volta potential difference between intermetallic and matrix is reduced: $-425 \mathrm{mV}$ before LSP and $-300 \mathrm{mV}$ after LSP (Fig. 11b). In that case, as LSP treatment tends to reduce the potential gradients, the microgalvanic coupling between the $\mathrm{Al}(\mathrm{CuFeMn})$ precipitates and the $\mathrm{Al}$ matrix are expected to be inhibited after LSP.

Statistically, on the 50 different precipitates considered on 3 different samples before and after LSP, 50\% of the observed precipitate-matrix potential gradients were not modified and 50\% were lowered by values ranging between $-50 \mathrm{mV}$ and $-150 \mathrm{mV}$. This reduction of potential gradients after LSP could contribute to explain the corrosion improvements obtained after LSP [10].

\section{Discussion}

Surface investigations carried out on a 2050-T8 laser-peened alloy have shown that on a very thin layer below the surface 

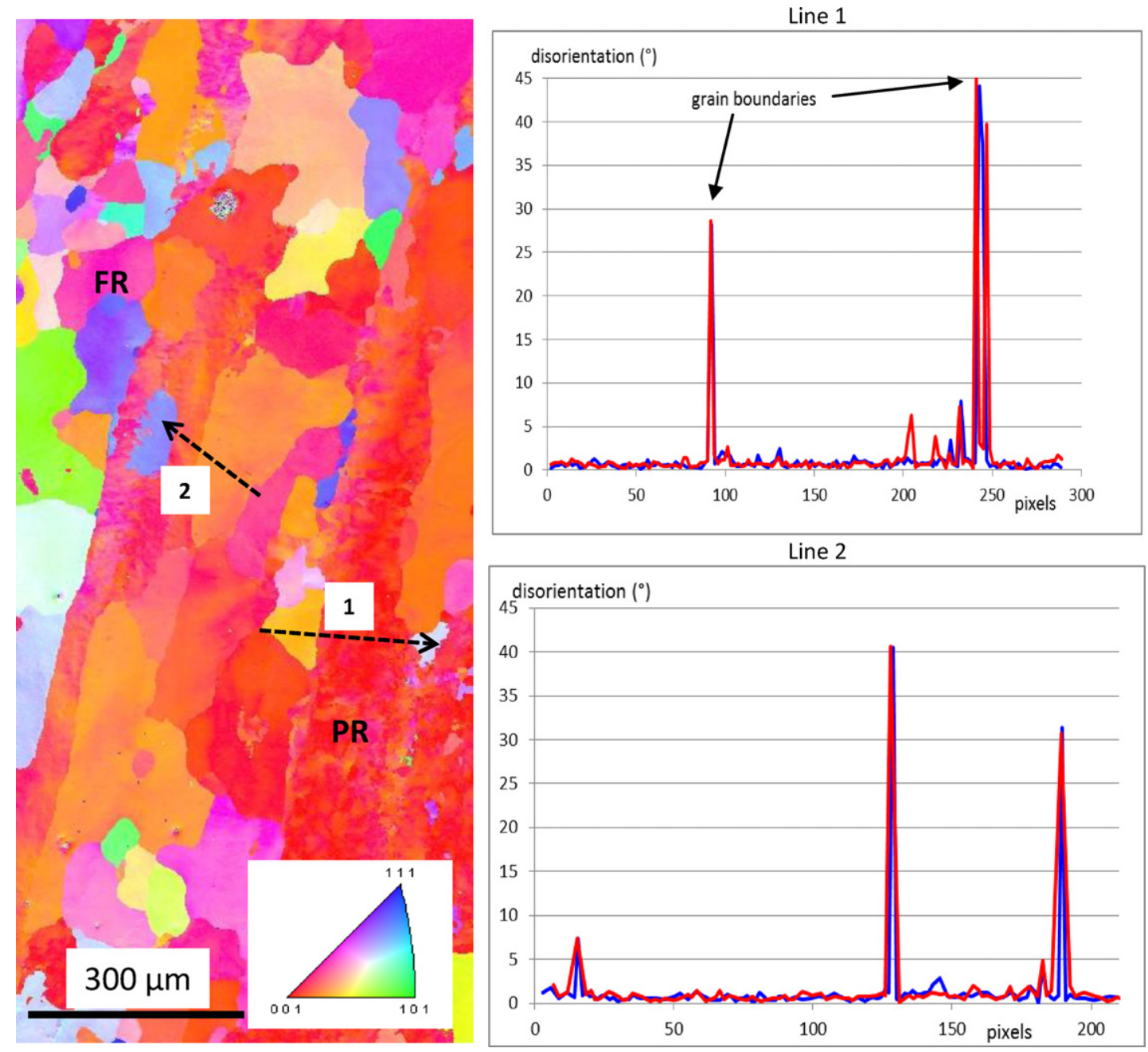

Fig. 12. EBSD analysis before and after LSP treatment (a) orientation map, (b) influence of LSP (blue = as-polished, red = laser-peened) on the crystal orientation.

(1-2 $\mu \mathrm{m})$, LSP did not create the work-hardening effect commonly expected from previous investigations. Below 1-2 $\mu \mathrm{m}$ depth, a more classical but limited ( $+20 \%$ maximum increase) workhardening is observed, together with a compressive stress field. As LSP is a mechanical surface treatment without contact, and without heating of the metal surface, this local phenomenon is rather hard to understand, and cannot be used to explain the improvement of corrosion resistance observed after LSP [10].

Many authors have studied recently the influence of elastic or plastic deformation on the work function of metal surface [23-27]. Even if theoretical or experimental data sometimes disagree concerning the real effect of stresses, it is now mostly recognized, for instance on $\mathrm{Al}$ and $\mathrm{Cu}$, that WF decrease with tensile elastic strains [27], and increase with elastic compressive strain [25,27]. The variation of WF is usually attributed to the variation of electron density of metallic surfaces: a compressive stress state tends to increase electron density and increase WF. Concerning plastic deformations most of the authors $[23,27]$ showed that both tensile and compressive strain decreased WF. In that case, the WF decrease was associated with the generation of a dislocation substructure which makes the surface more electrochemically active [23].

It is also known that the variation in the measured Volta or contact potential difference obtained by SKPFM is directly related to the difference $\Delta \Phi$ of WF between the metal and the probe, which is defined as the minimum energy required to remove an elec- tron from the Fermi level of the metal to a position just outside the metal surface. Consequently, SKPFM can provide us with useful information on the surface potential gradients after LSP.

On 2050-T8 aluminum alloy, two tendencies were observed after LSP treatment:

- either the $\mathrm{Al}(\mathrm{CuFeMn})$ precipitates-Al matrix gradients are kept constant, so that the micro-galvanic coupling between the precipitates and matrix is unchanged

- or these gradients are reduced by $-50 \mathrm{mV}$ to $-150 \mathrm{mV}$.

This result globally seems to agree with previous analytical and experimental works on work functions: as LSP causes low amplitude plastic deformation (approximately 1-2\% according to simulation data [28]) but induces high amplitude compressive residual strains and stresses (-300 Mpa surface value on 2050T8), an increase in work function is expected in the matrix. This WF increase could be responsible for the reduction of potential gradients in $50 \%$ of the observed precipitates.

The reason why the remaining precipitates (50\%) are not modified is not fully understood yet. This could not be related to a specific composition of the precipitates (\%Cu), or to their shape or their size. Moreover, precipitate vicinity, investigated by nanoindentation or EDS/MEB, did not reveal chemical or microstructural singularities around precipitates. Another explanation could come from the crystallographic orientations of grains containing precipi- 
tates. For instance, it could be expected that dense $\langle 111\rangle$ planes having high WF could be more sensitive to LSP treatment than other planes of the fcc lattice, and could promote a reduction of potential gradients. To support this assumption, and to point out a possible influence of LSP on local grain disorientations, electron back-scattered diffraction (EBSD) tests have been carried out before and after LSP treatment. Considering a 50\% overlap LSP treatment at $5 \mathrm{GW} / \mathrm{cm}^{2}$, results obtained are rather clear: whatever the $\mathrm{Al}$ grain orientation (Fig. 12), no modification of the disorientation appears between adjacent grains, and inside the grains the plastic deformation induced by LSP must have been too small to affect EBSD orientation. In our experimental conditions, it is interesting to note that EBSD investigates a nearly $0.05 \mu \mathrm{m}$ maximum depth for the backscattered electrons used in the Kikuchi lines formation and these backscattered electrons are from a energy close to the one of the primary beam [29]. This result can be easily correlated to nanoindentation tests which also did not demonstrate any work-hardening after LSP on the very first atomic surface layers.

This subject will have to be discussed with more detail in further publications, by correlating EBSD and SKPFM tests on the same areas, which work has already been done successfully in [30] on fully recrystallized $\mathrm{Cu}$ with micro-grains. In our case, this could be a little more difficult, due to the large grain sizes compared with AFM windows.

If we now try to compare our SKPFM results with local 2050T8 corrosion properties (huge improvement of the precipitate-free zones, little improvement of the precipitate areas independently of the grains observed [10]), we can assume that the observed reduction in Volta potential map near precipitates is probably not sufficient to modify the precipitate-matrix galvanic coupling. As potential gradients are still high after laser treatment, this could correspond to a non-detectable influence of LSP on the electrochemical behavior of precipitates-containing areas. The increase in WF with compressive stresses could also be correlated to a possible modification of anodic films formed in the matrix near precipitates, as pointed out by Amar et al. [10], but further experiments (impedance spectroscopy tests) should support this assumption.

To support the validity of our measurements and their significance regarding corrosion resistance, we can mention previous SKPFM studies on $\mathrm{Al}-\mathrm{Cu}-\mathrm{Mg}$ or $\mathrm{Al}-\mathrm{Zn}-\mathrm{Cu}-\mathrm{Mg}$ aluminum alloys which investigated the corrosion susceptibility on various precipitates [12,13,31]. Even though those SKPFM measurements were carried out in air, correlations were made between (1) SKPFM data, (2) the galvanic coupling between noble particles and Al-matrix, and (3) the resulting pitting corrosion resistance. More recent works focusing on the real significance of SKPFM measurements versus corrosion behavior on aluminum alloys [19] have indicated huge variations (from negative to positive) in potential values with the anodic oxide thickening, and with the global surface ageing. Even though experimental factors need to be taken into account [18], the correlation between corrosion behavior of an immersed aluminum sample and contact potential measurements of the same dry sample was admitted to be correct.

\section{Conclusions}

Different techniques were used to analyze surface modifications induced by a LSP treatment on a 2050-T8 aluminum alloy at a local scale, in order to provide an experimental support to the understanding of some recent corrosion resistance improvements obtained after LSP.

On the one hand, the first interesting result to mention is the negligible work-hardening and plastic deformation effect after LSP at the very surface of the alloy ( $1 \mu \mathrm{m}$ in-depth), evidenced by both EBSD analysis and nanoindentation tests, which had never been shown before on laser-peened surfaces, and which coexists with a global compressive stress field.

On the other hand, Volta potential maps were acquired with SKPFM on 2050-T8 alloy before and after LSP treatment. Such work was investigated to understand the electrochemical reactivity of the alloy after LSP, and more specifically possible changes in the galvanic coupling between the $\mathrm{Al}(\mathrm{CuFeMn})$ precipitates and AlCuLi matrix. Two distinct results were obtained: on half of the precipitates analyzed, precipitate-matrix gradients were kept constant, and on the remaining $50 \%$, they were reduced by $-50 \mathrm{mV}$ to $-150 \mathrm{mV}$. This modification of Volta potential gradients was attributed to an increase of the work function in the aluminum matrix due the LSP generation of compressive stresses, maybe assuming a more pronounced effect on well-oriented and dense crystallographic planes. However, preliminary EBSD trials did not evidence specific deformation patterns after LSP to support this assumption. Future work should address the grain-to-grain correlation of SKPFM and EBSD analysis.

\section{Acknowledgements}

This work was financially supported by the French Agence Nationale de la Recherche (ANR) under the framework of the CAPSUL project (ANR-07-BLAN-0198).

\section{References}

[1] P. Lequeu, K.P. Smith, A. Daniélou, Journal of Materials Engineering and Performance (2009), doi:10.1007/s11665-009-9554-Z.

[2] Z. Liu, F. Viejo, Z. Aburas, Y. Yuan, A. Gupta, Proceedings of ICALEO 2008 International Conference, Temecula (USA), 2008, pp. 447-452.

[3] F. Viejo, A.E. Coy, F.J. Garcia-Garcia, M.C. Merino, Z. Liu, P. Skeldon, G.E. Thompson, Thin Solid Films 518 (2010) 2722-2731.

[4] F. Viejo, A.E. Coy, F.J. Garcia-Garcia, Z. Liu, P. Skeldon, G.E. Thompson, Corrosion Science 52 (2010) 2179-2187.

[5] P. Peyre, B. Rouleau, H. Song, V. Vignal, H. Amar, H. Pelletier, J. Breuils, V. Ji, T. Baudin, J. Delfosse, 2nd LSP conference, (San Francisco), April, 2010.

[6] P. Peyre, R. Fabbro, P. Merrien, H.P. Lieurade, Materials Science and Engineering A210 (1996) 102-113.

[7] P. Peyre, X. Scherpereel, L. Berthe, C. Carboni, R. Fabbro, G. Béranger, C. Lemaitre Materials Science and Engineering A280 (2000) 294-302.

[8] P. Peyre, C. Carboni, P. Forget, G. Beranger, C. Lemaitre, D. Stuart, Journal of Materials Science 42 (2007) 6866-6877.

[9] P. Peyre, V. Vignal, H. Amar, H. Song, H. Pelletier, V. Ji, Proceedings of ICALEO 2009, International Conference, Orlando (USA), 2009, pp. 116-121.

[10] H. Amar, V. Vignal, H. Krawiec, O. Heintz, C. Josse, P. Peyre, Influence of a lasershock processing (LSP) treatment on the micro-electrochemical behavior of AA2050-T8, Electrochemica Acta (2010) (to be published).

[11] P. Schmutz, G.S. Frankel, Journal of Electrochemical Society 145 (7) (1998) 2285-2295.

[12] P. Campestrini, E.P.M. van Westing, H.W. van Rooijen, J.H.W. de Wit, Corrosion Science 42 (2000) 1853-1861.

[13] F. Andreatta, M.M. Lohrengel, H. Terryn, J.H.W. Wit, Electrochimica Acta 48 (2003) 3239-3247

[14] J.H.W. de Wit, Electrochimica Acta 49 (2004) 2841-2850.

[15] L.E. Fratila-Apachitei, I. Apachitei, J. Dusczczyk, Electrochimica Acta 51 (2006) 5892-5896.

[16] F. Andreatta, A. Turco, I. de Graeve, H. Terryn, J.H.W. de Wit, L. Fedrizzi, Surface and coatings Technology 201 (2007) 7668-7685.

[17] I. Apachitei, L.E. Fratila-Apachitei, J. Duszczyk, Scripta Materialia 57 (2007) 1012-1015.

[18] M. Rohwerder, F. Turcu, Electrochimica Acta 53 (2007) 290-299.

[19] T.H. Muster, A.E. Hugues, Journal of the Electrochemical Society 153 (11) (2006) B474-B485.

[20] B.S. Tanem, G. Svenningsen, J. Mardalen, Corrosion Science 47 (2005) 1506-1519.

[21] F.M. Serry, K. Kjoller, J.T. Thornton, R.J. Tench, D. Cook, Veeco Instruments Application Note AN27, (2004)

[22] C.B. Prater, P.G. Maivald, K.J. Kjoller, M.G. Heaton, Veeco Instruments Application Note AN04, (2004).

[23] W. Li, D.Y. Li, Applied Surface Science 240 (2005) 338-395.

[24] S.V. Loskutov, Surface Science 585 (2005) L166-L170.

[25] A.V. Babich, V.V. Pogosov, Surface Science 603 (2009) 2393-2397.

[26] W.G. Qin, D. Shawn, Physica B 404 (2009) 2247-2250.

[27] Y. Zhou, J.Q. Lu, W.G. Qin, Materials Chemistry and Physics 118 (2009) 12-14. 
[28] K. Ding, L. Ye, Surface Engineering 19 (5) (2003) 351-358.

[29] T. Baudin et, F. Brisset, L'EBSD: historique, principe et exemples d'applications, in: F. Brisset (Ed.), Microscopie Electronique à Balayage et Microanalyses, EDP Sciences, 2008, pp. 534-544, ISBN 978-2-7598-0082-7, Chapitre XVI.
[30] N. Gaillard, D. Mariolle, F. Bertin, M. Gros-Jean, M. Proust, A. Bsiesy, A. Bajolet, S. Chhun, M. Djebbouri, Microelectronic Engineering 83 (2006) 2169-2174.

[31] L. Lacroix, L. Ressier, C. Blanc, G. Mankowski, Journal of the Electrochemical Society 155 (1) (2008) C8-C15. 